\title{
HUBUNGAN DISFAGIA DAN PENURUNAN KESADARAN TERHADAP PNEUMONIA ASPIRASI PADA PASIEN STROKE RS ATMA JAYA
}

\author{
THE CORRELATION BETWEEN DISHAGIA AND ALTERED LEVEL OF CONSCIOUSNESS WITH \\ ASPIRATION PNEUMONIA IN STROKE PATIENTS AT ATMA JAYA HOSPITAL
}

Michael Nathaniel Budiarso, * Linda Suryakusuma, ${ }^{* *}$ Luse, ${ }^{* * *}$ Vetinly $* * * *$

\section{ABSTRACT}

Introduction: Approximately 40-96\% of stroke patients will develop complications; the most frequent is pneumonia (33\%). This is due to the underlying clinical manifestation of stroke such as dysphagia, immobilization, altered level of consciousness, and immune suppression which increases the risk of aspiration, therefore increases the risk for aspiration pneumonia. Early detection of aspiration pneumonia and its risk factors in stroke patients are essential, but the number of researches regarding this in Indonesia is still limited.

Aims: To study the correlation between dysphagia and altered level of consciousness in stroke patients with aspiration pneumonia in Atma Jaya Hospital, Jakarta.

Methods: This is a retrospective cohort research with a cross sectional approach towards 263 stroke patients in Atma Jaya Hospital, February 2016 until October 2017. Data was taken from the stroke registry and medical records, and analized with Chi-square test $(\alpha=0.05)$.

Results: The incidence for aspiration pneumonia was $16 \%$ in the study population, most of which being male $(57.8 \%)$, age $<65$ years old $(79.5 \%)$, and length of education $<9$ years $(71.5 \%)$. Age $\geq 65$, dysphagia and altered level of consciousness were statistically significant with Odds ratio (OR) 2.26, 3.92, and 8.67, respectively.

Discussion: Male, age $<65$ years old, and length of education $<9$ years were correlated with poor daily life habits which increases the risk of getting a stroke. Age $\geq 65$ years old, dysphagia and altered level of consciousness can disturb the coordination and swallowing reflex which makes patients more vulnerable to aspiration and develop aspiration pneumonia.

Keywords: Altered level of consciousness, aspiration pneumonia, dysphagia, stroke

\section{ABSTRAK}

Pendahuluan: Sebanyak 40-96\% pasien stroke akan mengalami komplikasi, terutama pneumonia (33\%). Hal ini dimungkinkan oleh adanya kecenderungan disfagia, imobilitas, penurunan kesadaran, dan supresi imunitas yang mempermudah terjadinya aspirasi hingga terjadi pneumonia aspirasi. Deteksi awal faktor risiko pneumonia aspirasi pada pasien stroke sangat penting, namun penelitiannya masih terbatas di Indonesia.

Tujuan: Mengetahui hubungan antara disfagia dan penurunan kesadaran terhadap kejadian pneumonia aspirasi pada pasien stroke di RS Atma Jaya, Jakarta.

Metode: Penelitian kohort retrospektif dengan pendekatan potong lintang terhadap 263 pasien stroke di RS Atma Jaya. Penelitian dilakukan mulai Februari 2016-Oktober 2017. Data diperoleh melalui data register stroke dan rekam medis. Analisis dilakukan menggunakan uji Chi-square dengan nilai $\alpha=0,05$.

Hasil: Insiden pneumonia aspirasi pada pasien stroke adalah 16\%. Didapatkan mayoritas populasi laki-laki (57,8\%) berusia $<65$ tahun $(79,5 \%)$, dan berpendidikan $<9$ tahun $(71,5 \%)$. Usia $\geq 65$ tahun, disfagia, dan penurunan kesadaran memiliki hubungan yang bermakna secara statistik terhadap kejadian pneumonia aspirasi dengan rasio Odds (RO) 2,26, 3,92, dan 8,67 kali lipat.

Diskusi: Laki-laki, usia $<65$ tahun, dan pendidikan $<9$ tahun berkaitan dengan pola kesehatan hidup buruk yang meningkatkan faktor risiko terjadinya stroke. Usia $\geq 65$ tahun, disfagia, dan penurunan kesadaran dapat mengganggu koordinasi dan refleks menelan, sehingga pasien stroke lebih rentan terjadi aspirasi dan mengalami pneumonia aspirasi.

Kata kunci: Disfagia, penurunan kesadaran, pneumonia aspirasi, stroke

*FK Universitas Katolik Indonesia Atma Jaya, Jakarta; **Departemen Neurologi FK Universitas Katolik Indonesia Atma Jaya, Jakarta; ***Departemen Ilmu Penyakit Dalam FK Universitas Katolik Indonesia Atma Jaya, Jakarta; ****Departemen Ilmu Kesehatan Masyarakat-Gizi FK Universitas Katolik Indonesia Atma Jaya, Jakarta. Korespondensi: michaelnathanielb@gmail.com.

\section{PENDAHULUAN}

Stroke merupakan kondisi terganggunya distribusi darah ke otak yang dapat disebabkan penyumbatan atau pecahnya pembuluh darah otak dan hal ini dapat menyebabkan kerusakan jaringan otak. ${ }^{1}$ Stroke menempati urutan tertinggi penyebab kematian di dunia. ${ }^{2}$ Stroke di Indonesia menurut data yang diambil dari Riset Kesehatan Daerah tahun 2013 merupakan penyebab kematian tertinggi dengan prevalensi 12,1 per 1.000 penduduk. $^{3}$ Pasien stroke 
sangat rentan terkena komplikasi penyakit lainnya dengan risiko berkisar antara 40-96\%. ${ }^{4}$

Pneumonia merupakan komplikasi yang paling sering terjadi dengan jumlah mencapai sepertiga dari seluruh pasien stroke dan merupakan penyebab kematian tertinggi dibandingkan semua komplikasi pada pasien stroke lainnya. ${ }^{5}$ Pneumonia pada pasien stroke terutama terjadi pada minggu pertama yang berkaitan dengan kejadian disfagia, imobilitas, penurunan kesadaran, dan supresi respons imun. ${ }^{6}$

Komplikasi pneumonia yang terjadi pada pasien stroke akan menghambat kesembuhan optimal serta meningkatkan angka morbiditas, mortalitas, dan beban pengeluaran biaya pengobatan pasien. ${ }^{7}$

Pneumonia yang terjadi pada pasien stroke umumnya disebabkan mekanisme aspirasi. ${ }^{5,7-9}$ Kecenderungan pasien stroke untuk terkena disfagia dan penurunan kesadaran ditemukan sebagai faktor risiko penting yang mempermudah terjadinya aspirasi. ${ }^{7,10-13}$ Prevalensi pasien stroke yang terkena disfagia berkisar antara $28-65 \%$, sedangkan yang mengalami penurunan kesadaran antara 4-38\%. ${ }^{11,13-14}$ Keduanya diketahui dapat memengaruhi koordinasi dan refleks yang berkaitan dengan penelanan, yang akhirnya meningkatkan kemungkinan terjadinya aspirasi. . $^{5,710,12}$.

Penelitian telah membuktikan bahwa deteksi awal faktor-faktor pendukung terjadinya aspirasi pada pasien stroke tidak hanya mengurangi risiko pneumonia aspirasi yang sering menimbulkan kematian, melainkan juga mengurangi waktu perawatan di rumah sakit, serta beban biaya pengobatan; sayangnya penelitian mengenai stroke dan pneumonia aspirasi di Indonesia, khususnya faktor risiko spesifik seperti disfagia dan penurunan kesadaran masih terbatas. ${ }^{5}$ Oleh karena itu, perlu dilakukan penelitian mengenai faktor penting aspirasi pada stroke, yaitu disfagia dan penurunan kesadaran, terhadap kejadian pneumonia aspirasi.

\section{TUJUAN}

Mengetahui insiden pneumonia aspirasi serta hubungannya dengan disfagia dan penurunan kesadaran pada pasien stroke di RS Atma Jaya, Jakarta.

\section{METODE}

Penelitian ini bersifat kohort retrospektif dan merupakan bagian dari penelitian kohort Departemen Neurologi Fakultas Kedokteran Unika Atma Jaya terhadap seluruh pasien stroke yang dirawat di

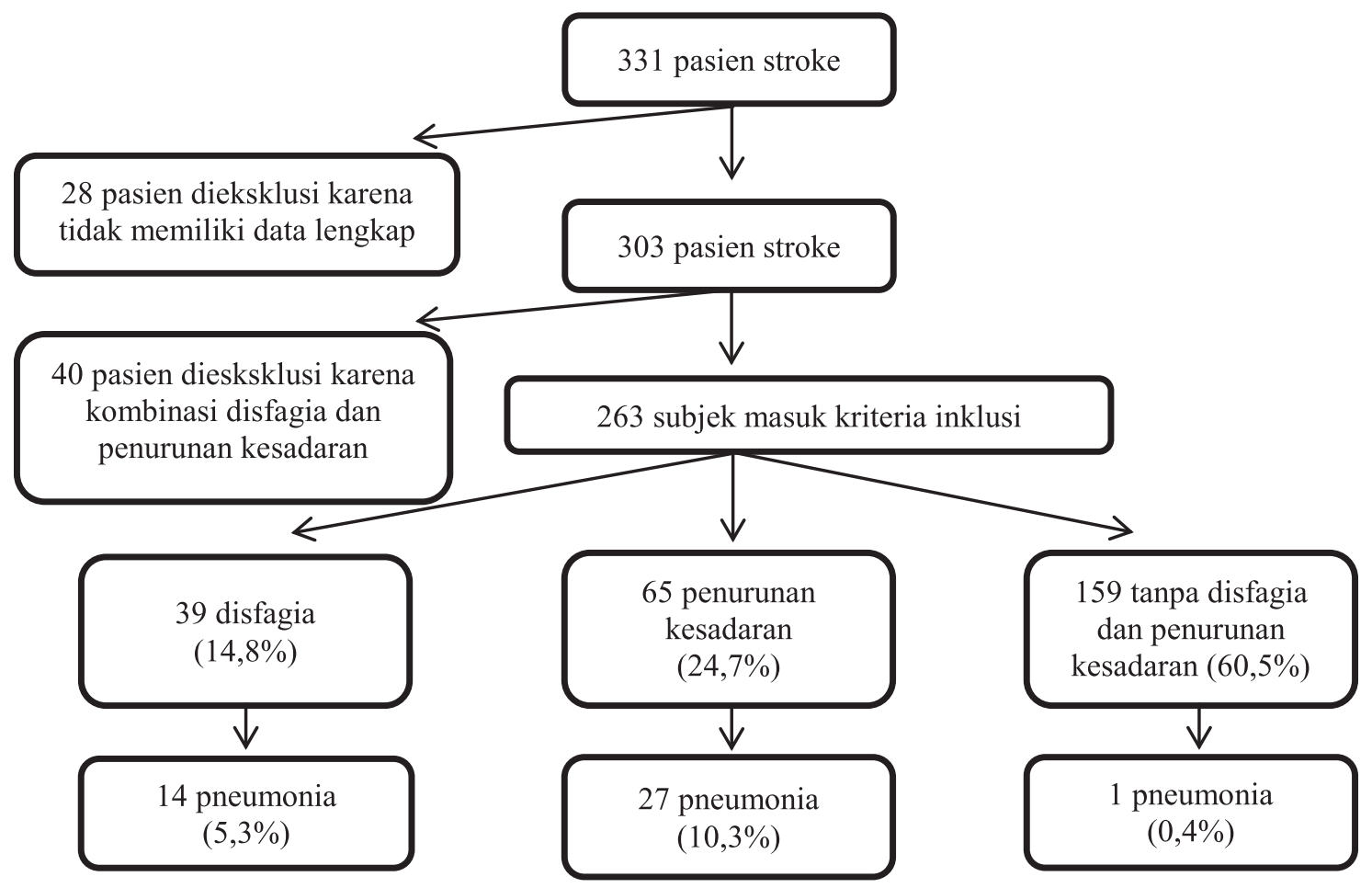

Gambar 1. Pengaruh Disfagia dan Penurunan Kesadaran terhadap Pneumonia Aspirasi 
RS Atma Jaya pada periode Maret 2014 hingga Desember 2016.

Data diambil melalui register stroke yang dicocokkan dengan rekam medis berupa data demografik (jenis kelamin, usia, dan pendidikan), serta data klinis pasien stroke yang dicurigai mengalami aspirasi dengan gejala disfagia, penurunan

Tabel 1. Karakteristik Subjek Penelitian $(n=263)$

\begin{tabular}{lc}
\hline \multicolumn{1}{c}{ Variabel } & n (\%) \\
\hline Jenis Kelamin & \\
- Laki-laki & $152(57,8)$ \\
- Perempuan & $111(42,2)$ \\
Usia & \\
- $\geq 65$ tahun & \\
- $<65$ tahun & $54(20,5)$ \\
Pendidikan & $209(79,5)$ \\
- $<9$ tahun & \\
- $\geq 9$ tahun & $188(71,5)$ \\
Pneumonia Aspirasi & $75(28,5)$ \\
- Ya & \\
- Tidak & $42(16)$ \\
Disfagia & $221(84)$ \\
- Ya & \\
- Tidak & $39(14,8)$ \\
Penurunan Kesadaran & $224(85,2)$ \\
- Ya & \\
- Tidak & $65(24,7)$ \\
\hline
\end{tabular}

Tabel 2. Hubungan antara Karakteristik Demografik dengan Pneumonia Aspirasi (n=263)

\begin{tabular}{lccccc}
\hline \multicolumn{1}{c}{ Variabel } & \multicolumn{2}{c}{$\begin{array}{c}\text { Pneumonia } \\
\text { Aspirasi }\end{array}$} & Total & p* & $\begin{array}{c}\text { Rasio } \\
\text { Odds }\end{array}$ \\
\cline { 2 - 3 } & Ya & Tidak & & & \\
\hline Jenis Kelamin & & & & & \\
- Laki-laki & 24 & 128 & 152 & & \\
- Perempuan & 18 & 93 & 111 & 0,926 & 0,97 \\
Usia & & & & & \\
$\bullet \geq 65$ tahun & 14 & 40 & 54 & & \\
- $<65$ tahun & 28 & 181 & 209 & 0,025 & 2,26 \\
Pendidikan & & & & & \\
- $<9$ tahun & 30 & 158 & 188 & & \\
$\bullet \geq 9$ tahun & 12 & 63 & 75 & 0,993 & 1,00 \\
Total & 42 & 221 & 263 & & \\
\hline
\end{tabular}

*Uji Chi-square. kesadaran, dan pneumonia aspirasi. Gejala disfagia berdasarkan adanya gangguan menelan, penurunan kesadaran dilihat dari Skala Koma Glasgow $<15$ dan pneumonia aspirasi dilihat dari data klinis dan konfirmasi hasil foto toraks.

Kriteria eksklusi berupa data yang tidak lengkap, transient ischemic attack (TIA), mengalami kombinasi gangguan kesadaran dan menelan sekaligus, atau telah mengalami gangguan kesadaran, gangguan refleks menelan, dan pneumonia sebelumnya.

Analisis statistik menggunakan SPSS 22.0. Kemaknaan statistik menggunakan uji Chi-square dengan nilai $\alpha=0,05$, serta melihat rasio Odds (RO) dari masing-masing variabel.

\section{HASIL}

Terdapat 303 pasien yang memiliki data yang lengkap dari 331 pasien stroke yang dirawat selama periode Maret 2014 hingga Desember 2016, namun hanya 263 data yang sesuai dengan kriteria inklusi dan eksklusi. Mayoritas subjek adalah laki-laki $(57,8 \%)$, berusia $<65$ tahun $(79,5 \%)$, dan berpendidikan $\leq 9$ tahun (71,5\%). Sebanyak 16\% subjek yang mengalami pneumonia aspirasi, 14,8\% subjek mengalami disfagia, dan $24,7 \%$ dengan penurunan kesadaran (Tabel 1).

Tabel 2 menunjukkan bahwa subjek berusia $\geq 65$ tahun cenderung mengalami kejadian pneumonia aspirasi 2,26 kali lebih tinggi dibandingkan subjek yang berusia $<65$ tahun secara bermakna $(p=0,025)$. Adapun jenis kelamin dan pendidikan tidak berpengaruh bermakna terhadap kejadian pneumonia aspirasi.

Tabel 3. Hubungan antara Disfagia dan Penurunan Kesadaran Demografik dengan Pneumonia Aspirasi (n=263)

\begin{tabular}{lccccc}
\hline \multirow{2}{*}{ Variabel } & \multicolumn{2}{c}{$\begin{array}{c}\text { Pneumonia } \\
\text { Aspirasi }\end{array}$} & Total & p* & $\begin{array}{r}\text { Rasio } \\
\text { Odds }\end{array}$ \\
\cline { 2 - 3 } Ya & Tidak & & & \\
\cline { 1 - 4 } - Ya & 14 & 25 & 39 & & \\
- Tidak & 28 & 196 & 224 & $<0,001$ & 3,92 \\
Penurunan & \multicolumn{7}{c}{ Kesadaran } & & & \\
- Ya & 27 & 38 & 65 & & \\
- Tidak & 15 & 183 & 198 & $<0,001$ & 8,67 \\
\hline
\end{tabular}

*Uji Chi-square. 
Sebanyak 14,8\% subjek mengalami disfagia, yang 35,9\% diantaranya mendapatkan komplikasi pneumonia aspirasi (Tabel 3). Hal ini menunjukkan subjek dengan disfagia akan mengalami kejadian pneumonia aspirasi dengan rasio Odds (RO) 3,92 kali dibandingkan yang tidak mengalami disfagia secara bermakna $(\mathrm{p}<0,001)$.

Terdapat $24,7 \%$ subjek yang mengalami penurunan kesadaran yang diantaranya $(41,5 \%)$ mengalami pneumonia aspirasi. Uji Chi-square didapatkan hubungan bermakna antara penurunan kesadaran terhadap kejadian pneumonia aspirasi $(p<0,001)$ dengan angka RO 8,67 kali lebih tinggi dibandingkan subjek yang sadar.

\section{PEMBAHASAN}

Berdasarkan penelitian Chapman dkk dan Wandira dkk, prevalensi kejadian pneumonia setelah terkena stroke berkisar antara 10-33\%, sesuai dengan penelitian ini $(16 \%))^{5,17}$ Hasil ini menunjukkan bahwa pasien stroke merupakan populasi yang rentan mengalami pneumonia akibat aspirasi. Hal ini terjadi akibat kombinasi penurunan daya tahan tubuh yang disebabkan oleh penyakit stroke sendiri, ditambah terganggunya fungsi dan koordinasi menelan akibat cedera neurologis yang meningkatkan kemungkinan aspirasi, seperti disfagia dan penurunan kesadaran. ${ }^{5-13,17}$

Dominasi laki-laki sesuai dengan penelitian Wandira dkk, Ganz dkk, dan Poorthuis dkk, bahwa stroke lebih sering pada laki-laki dibandingkan perempuan. Hal ini berhubungan dengan multi faktor seperti genetik, efek protektif estrogen pada sirkulasi serebral perempuan, serta tingginya angka prevalensi hipertensi, penyakit jantung iskemik, dan merokok pada laki-laki. ${ }^{17-19}$

Hasil yang menunjukkan bahwa lebih banyak pasien stroke laki-laki yang mengalami pneumonia aspirasi juga sesuai dengan Wandira dkk dan Matz dkk sebelumnya, meskipun pada penelitian ini tidak didapatkan hasil yang bermakna secara statistik. ${ }^{17,20}$ Matz dkk dan Hoffmann dkk mengatakan bahwa perempuan memiliki gaya hidup yang lebih sehat dengan konsumsi alkohol dan merokok yang lebih kecil, serta efek protektif dari hormon seks yang menginhibisi reaksi inflamasi yang dihasilkan antigen bakteri. Semua ini menghasilkan risiko dan tingkat keparahan infeksi paru-paru yang lebih kecil pada perempuan, meskipun Hoffmann dkk mengatakan ada beberapa studi lain yang tidak menemukan asosiasi jenis kelamin tersebut sehingga membutuhkan investigasi lebih lanjut. ${ }^{20-21}$

Dominasi pasien stroke berusia dibawah 65 tahun sesuai dengan penelitian usia terjadinya stroke di Asia, yaitu terjadi penurunan insiden stroke secara signifikan pada kelompok usia $>50$ tahun. Sebaliknya terjadi peningkatan insiden stroke pada usia dibawah 50 tahun. ${ }^{23}$ Kim dkk menemukan bahwa mereka yang tinggal di kawasan Asia lebih rentan untuk terkena stroke di usia yang lebih muda dibandingkan mereka yang tinggal di negara Barat. Hal ini berhubungan erat dengan populasi Asia yang mengonsumsi rokok dengan jumlah terbesar di dunia, kebiasaan diet tinggi karbohidrat dan garam serta rendah lemak, dan status sosio-ekonomi yang lebih rendah dibandingkan populasi negara Barat. Terjadi peningkatan prevalensi hipertensi, diabetes, dan hiperkolesterolemia, yang akhirnya menambah angka kejadian stroke pada mereka yang lebih muda di Asia, termasuk Indonesia. ${ }^{22}$

Penelitian ini juga mendapatkan hubungan bermakna antara peningkatan usia pada pasien stroke terhadap kejadian pneumonia aspirasi dengan RO 1,92 kali. Hal ini sesuai dengan Wandira dkk, dan Ebihara dkk sebelumnya yang mengatakan bahwa peningkatan usia berbanding lurus dengan peningkatan terjadinya pneumonia. Faktor-faktor yang meningkatkan risiko kejadian pneumonia pada orang lanjut usia adalah penurunan fisiologis paruparu (penurunan daya tahanan elastis, peningkatan udara yang terperangkap karena emfisema senilis, penurunan daya kembang paru, dan penurunan kekuatan otot respirasi), penurunan kemampuan mukosilier untuk membersihkan benda asing, penurunan refleks batuk, penurunan sistem imun humoral dan seluler serta penurunan fungsi kognitif. ${ }^{17,24}$ Penurunan fisiologis yang terjadi membuat pasien stroke yang berusia tua rentan mengalami aspirasi yang tidak terdeteksi, dan berakhir dengan kejadian pneumonia aspirasi. ${ }^{24}$ 
Dominasi pendidikan rendah di penelitian ini sesuai dengan Nordahl dkk. Hal ini terjadi karena terdapat hubungan antara pendidikan rendah dengan perilaku tidak sehat seperti merokok dan juga penyakit-penyakit yang meningkatkan kemungkinan terjadinya stroke seperti hipertensi, masalah jantung, dan diabetes melitus. ${ }^{25}$ Penelitian ini juga menunjukkan bahwa meskipun pendidikan rendah mendominasi jumlah pasien stroke, angka ini tidak memiliki hubungan yang bermakna secara statisik terhadap kejadian pneumonia aspirasi. Hal ini berbeda dengan kejadian pneumonia komunitas secara umum yang tidak didahului stroke, dimana penelitian Muthumbi dkk mendapati apabila faktor pendidikan rendah berpengaruh pada risiko peningkatan angka pneumonia komunitas secara umum. ${ }^{26}$

Jumlah pasien stroke yang mengalami disfagia pada penelitian ini lebih kecil dibandingkan Chapman dkk, Cohen dkk, dan Rao dkk sebelumnya (28$65 \%) .{ }^{5,11,13}$ Perbedaan ini dapat terjadi karena peneliti mengeksklusi pasien dengan kombinasi disfagia dan penurunan kesadaran untuk mencari hubungan spesifik dari masing-masing faktor risiko tersebut dalam meningkatkan kemungkinan pneumonia aspirasi. Juga terdapat perbedaan keterbatasan pemeriksaan fungsi menelan pada subjek yang tidak menggunakan standar baku alat fluoroskopi dan endoskopi optik serat karena harga yang tidak murah dan kurang fleksibel. Diagnosis disfagia pada penelitian ini menggunakan pengujian kompetensi organ oral dan faring. Namun sekitar $40 \%$ aspirasi pada pasien disfagia sering kali tidak disertai dengan tanda-tanda yang jelas, sehingga membuat disfagia sulit dideteksi dengan pemeriksaan yang berdasarkan gambaran klinis saja. ${ }^{11}$

Penelitian ini mendapatkan disfagia memiliki hubungan yang bermakna terhadap pneumonia aspirasi dengan RO 2,28 kali. Hal ini sesuai dengan Chapman dkk, dengan RO berkisar antara 1,89 hingga 15,56 kali. ${ }^{5}$ Adanya bakteri dengan virulensi rendah pada sekresi faring yang dijaga oleh koordinasi pernapasan dan penelanan yang baik ditambah mekanisme imun humoral dan seluler yang baik, akan mencegah seseorang terhadap pneumonia aspirasi. ${ }^{7}$ Westendorp dkk menemukan aspirasi terjadi pada $33-50 \%$ pasien stroke yang disfagia, sedangkan pasien yang mengalami aspirasi akan meningkatkan risiko terjadinya pneumonia hingga 11 kali lipat. ${ }^{27}$ Hasil yang menunjukkan mereka yang tidak mengalami disfagia tetap bisa terkena pneumonia aspirasi, kemungkinan disebabkan mekanisme faktor lain, seperti posisi pasien, ventilasi mekanis, dan gangguan mobilitas pasien. ${ }^{28}$

Jumlah pasien stroke yang mengalami penurunan kesadaran pada penelitian ini sesuai dengan Li dkk yang berkisar antara $4-38 \% .{ }^{14}$ Penurunan kesadaran pada pasien stroke lebih umum terjadi pada stroke perdarahan dan merupakan salah satu faktor yang menentukan prognosis mortalitas pasien. ${ }^{29}$ Pada penelitian ini tidak dilakukan pembagian jenis stroke antara stroke perdarahan dan iskemik, karena itu mungkin akan terjadi perbedaan persentase pada studi yang spesifik meneliti penurunan kesadaran pada pasien stroke.

Penelitian ini mendapatkan penurunan kesadaran pada pasien stroke akan meningkatkan angka kejadian komplikasi pneumonia aspirasi, sesuai dengan Wandira dkk bahwa 79,2\% pasien stroke yang mengalami pneumonia mengalami penurunan kesadaran. Hal ini berhubungan dengan penurunan protektif refleks batuk, gangguan fungsi sfingter bawah esofagus, dan gangguan koordinasi antara bernapas dan menelan yang memiliki efek yang sama dengan disfagia. ${ }^{17}$ Penelitian sebelumnya mendapatkan perbedaan risiko aspirasi pada seseorang dengan nilai Skala Koma Glasgow $<8$ karena hilangnya fungsi protektif dari mekanisme aspirasi. ${ }^{10}$ Belum ditelitinya nilai Skala Koma Glasgow spesifik pada pasien stroke yang berpengaruh terhadap peningkatan risiko aspirasi membuat dibutuhkannya penelitian lanjutan untuk menjawab hal ini.

Pada penelitian ini ditemukan kendala banyaknya data tidak lengkap pada register stroke. Penelitian ini juga memiliki keterbatasan karena berdasarkan data sekunder. Hal ini membuka peluang untuk penelitian lanjutan dengan menggunakan data primer. 


\section{KESIMPULAN}

Insiden pneumonia aspirasi pada pasien stroke di RS Atma Jaya 16\%. Usia >65 tahun, disfagia, dan penurunan kesadaran memiliki hubungan yang bermakna terhadap kejadian pneumonia aspirasi pada pasien stroke dengan RO masing-masing 2,26 kali, 3,92 kali, dan 8,67 kali.

\section{DAFTAR PUSTAKA}

1. World Health Organization. Stroke, cerebrovascular accident; 2014.

2. World Health Organization. The top 10 causes of death; 2016.

3. Badan Penelitian dan Pengembangan Kesehatan. Riset Kesehatan Dasar (Riskesdas 2013); 2013.

4. Wen CP, Liu C, Jeng J, Hsu S, Chen C, Lien L, dkk. Pre-stroke physical activity is associated with fewer post-stroke complications, lower mortality, and a better long-term outcome. Eur J Neurol. 2017;24(12):1525-31.

5. Chapman C, Morgan P, Cadilhac D, Purvis T, Andrew N. Risk factors for the development of chest infections in acute stroke: A systematic review. Top Stroke Rehabil. 2018;25(6):445-58.

6. Smith CJ, Kishore AK, Vail A, Chamorro A, Garau J, Hopkins SJ, dkk. Diagnosis of stroke-associated pneumonia. Stroke. 2015;46(8):2335-40.

7. Hannawi Y, Hannawi B, Rao CPV, Suarez JI, Bershad EM. Stroke-associated pneumonia: Major advances and obstacles. Cerebrovasc Dis Basel Switz. 2013;35(5):430-43.

8. Watanabe $\mathrm{S}$, Shimozato K, Oh-Shige H, Umemura M, Fujiwara S, Abe Y, dkk. Examination of factors associated with aspiration pneumonia following stroke. Oral Sci Int. 2014;11(1):15-21.

9. Castillo L, Sumalapao DE, Pascual JL. Risk factors for pneumonia in acute stroke patients admitted to the emergency department of a tertiary government hospital. Natl J Physiol Pharm Pharmacol. 2017;7(8):855-9.

10. Rotheray KR, Cheung PSY, Cheung CSK, Wai AKC, Chan DYS, Rainer TH, dkk. What is the relationship between the Glasgow coma scale and airway protective reflexes in the Chinese population? Resuscitation. 2012;83(1):86-9.

11. Cohen DL, Roffe C, Beavan J, Blackett B, Fairfield CA, Hamdy S, dkk. Post-stroke dysphagia: A review and design considerations for future trials. Int $\mathrm{J}$ Stroke. 2016;11(4):399-411.

12. Zhao J, Liu Y, Li H. Aspiration-related acute respiratory distress syndrome in acute stroke patient.
PLoS One. 2015;10(3):e0118682.

13. Rao S, Shahzad A, Sumaira N, Mansoor I. The burden of dysphagia and chest infection in acute ischemic stroke in a tertiary care hospital of islamabad capital territory. PJNS. 2014;9(4):4.

14. Li J, Wang D, Tao W, Dong W, Zhang J, Yang J, dkk. Early consciousness disorder in acute ischemic stroke: incidence, risk factors and outcome. BMC Neurol. 2016;16:140.

15. Naja S, Makhlouf M, Chehab M. An ageing world of the 21 st century: A literature review. Int J Community Med Public Health. 2017;4(12):4363-9.

16. Presiden Republik Indonesia. Peraturan Pemerintah Republik Indonesia nomor 66 tahun 2010; 2010.

17. Wandira RD, Amalia L, Fuadi I. Hubungan antara derajat keparahan stroke dengan kejadian strokeassociated pneumonia. Neurona. 2018;35(2):116-20.

18. Gan Y, Wu J, Zhang S, Li L, Yin X, Gong Y, dkk. Prevalence and risk factors associated with stroke in middle-aged and older Chinese: A community-based cross-sectional study. Sci Rep. 2018;8:4563.

19. Poorthuis MH, Algra AM, Algra A, Kappelle LJ, Klijn CJ. Female- and male-specific risk factors for stroke: A systematic review and meta-analysis. JAMA Neurol. 2017;74(1):75-81.

20. Matz K, Seyfang L, Dachenhausen A, Teuschl Y, Tuomilehto J, Brainin M. Post-stroke pneumonia at the stroke unit-a registry based analysis of contributing and protective factors. BMC Neurol. 2016;16:107.

21. Hoffmann S, Malzahn U, Harms H, Koennecke HC, Berger K, Kalic M, dkk. Development of a clinical score (A2DS2) to predict pneumonia in acute ischemic stroke. Stroke. 2012;43(10):2617-23.

22. Kim YD, Jung YH, Saposnik G. Traditional risk factors for stroke in East Asia. J Stroke. 2016;18(3):273-85.

23. Tan CS, Muller-Riemenschneider F, Ng SHX, Tan PZ, Chan BPL, Tang KF, dkk. Trends in stroke incidence and 28-day case fatality in a nationwide stroke registry of a multiethnic Asian population. Stroke. 2015;46(10):2728-34.

24. Ebihara S, Sekiya H, Miyagi M, Ebihara T, Okazaki T. Dysphagia, dystussia, and aspiration pneumonia in elderly people. J Thorac Dis. 2016;8(3):632-9.

25. Nordahl H, Osler M, Frederiksen BL, Andersen I, Prescott E, Overvad K, dkk. Combined effects of socioeconomic position, smoking, and hypertension on risk of ischemic and hemorrhagic stroke. Stroke. 2014;45(9):2582-7.

26. Muthumbi E, Lowe BS, Muyodi C, Getambu E, Gleeson F, Scott JAG. Risk factors for communityacquired pneumonia among adults in Kenya: A casecontrol study. Pneumonia. 2017;9:17. 
27. Westendorp WF, Nederkoorn PJ, Vermeij JD, Dijkgraaf MG, Van-De-Beek D. Post-stroke infection: A systematic review and meta-analysis. BMC Neurol. 2011;11:110.

28. Immunomodulation after ischemic stroke: Potential mechanisms and implications for therapy. Critical
Care. 2017;21:256.

29. Sarkar D, Halder S, Saha BK, Biswas P. A study of stroke patients with respect to their clinical and demographic profile and outcome. Int J Res Med Sci. 2016;4(9):4061-6. 